\title{
LA ESCRITURA SIN CENTRO: TRES CALAS EN LA POESÍA DE ANTONIO MARTÍNEZ SARRIÓN
}

ANTONIO MÉNDEZZ RUBio

Universitat de València

RESUMEN

La poesía de Antonio Martínez Sarrión constituye un lugar interesante, incluso desafiante, en relación con las formas de la teoría literaria herederas del paradigma mimético o realista —en el sentido más tradicional de este término. La apuesta de esta escritura por la visibilización de procesos de montaje discursivo, su densidad significante que problematiza la hegemonía de todo Significado, articula así una autoconciencia ideológicamente crítica que singulariza estos textos así como sus propuestas de lectura.

Las relaciones entre discurso y mundo ponen a la vista, entre otros, un punto fundamental: ninguno puede pensarse sin el otro. Su distinción es sólo abstracta. De una manera $u$ otra, cada discurso se da comprometido con una situación y una posición de modo que, consciente o inconscientemente, no deja de encarnar visiones instables de mundo, espacios de proyección ideológica sobre/desde el propio contexto en que toma cuerpo. Por esto, no parece viable desatender la dimensión política, en sentido amplio, de ese cristal sígnico de cuyas infinitas texturas depende no sólo nuestra concepción de las relaciones sociales sino las diferentes posibilidades de participar en ellas a través de prácticas compartidas. 
Una acepción ancha de la escritura en tanto práctica lingüística (de)generadora de (sentidos de) mundo hace más accesible indagar en la multiplicidad irreductible de caminos por los que la imbricación de lo poético y lo político se plantea. Así, parafraseando a Rossi-Landi (1980), puede entenderse por escritura revolucionaria aquella práctica poética donde la puesta en conflicto, en crisis, de la tensión significante impida reducir el sentido a las dimensiones instrumentales $u$ omamentales que el uso conservador prefiere: un trabajo con la $\mathrm{f}(\mathrm{r})$ actura formal que remueva radicalmente no sólo este tipo de usos sino también el propio concepto unitario y fijo de sentido. Lo inaccesible entonces es la centralidad del significado.

En efecto, desde este punto de vista, la noción de práctica poética se cruza con las acepciones no epocales de la vanguardia como matriz (de)constructiva de discurso cuya atención se descentra en el carácter abierto de los procesos materiales que la realizan. Se opone, así, tanto a la estrategia fetichista de privilegio de los efectos característica del kitsch y la tragedia clásica como a los códigos de autoría y propiedad del mercantilismo. Como ocurre en el jazz, que el texto, su f(r)actura, se encarne históricamente como crisis capacita entonces al discurso para afrontar los desafíos móviles de su labor crítica.

Asimismo, la vinculación de las nociones de práctica y de técnica podría contribuir a salir del cerco esencialista e idealista que a la convención literatura han venido poniendo tanto la teoria de los géneros de Aristóteles como la concepción de lo estético como expresión subjetiva en la línea de Croce y de la linguística de Humboldt. En una palabra: podría poner en duda, desde cada ámbito operativo concreto, la solidez del pensamiento (institucionalizado como) moderno así como los modos de organización social que éste legitima, básicamente, el Individuo, el Estado y el Mercado capitalista. Ensanchando la técnica más allá del terreno textual hacia la consideración de sus implicaciones en los procesos generales de producción social, Benjamín (1990: 137) pensaba, en efecto, que «un criterio decisivo de una función revolucionaria de la literatura consistiría en la medida de los progresos técnicos que desembocan en una transformación funcional de las formas del arte y por tanto de los medios espirituales de producción». Por esta vía resultan ilustrativas las aportaciones de Lev Kuleshov a la investigación filmica: su visión del discurso como medium material y dinámico reconecta -ignorando la Estética - el tradicional y esterilizante seccionamiento de técnica, historia y arte. El trabajo retórico, el principio de montaje, desplaza la atención del significado o el significante a la pluralidad de sus modos de relación así como pone de manifiesto las interferencias de realidad y ficción, y, con ello, los desafíos del carácter agitador de ésta y alterable de aquélla (Mariniello, 1992).

En este sentido, «es evidente que la realidad exterior pesa, pero lo que otorga significado válido a lo que un espacio textual parece decir es la organización de su dicción. Que el espacio textual es un reflejo del mundo es algo fuera de to- 
da duda, pero entendiendo reflejo en el sentido leninista de reflejo sin espejo, esto es, no de manera pasiva, sino como inscripción en el proceso dialéctico de una transformación» (Talens/Company/Hernández, 1985: 547). El marco dialógico que mueve el par espacio textual/lectura puede ser prefigurado por el primero con mayor o menor intensidad según diferentes grados de riesgo para su entereza estructural. A este nivel -materialmente registrable, históricamente activo, la dialogización del discurso con otros textos y/o con sus propias premisas deja de ser un determinado esquema descriptivo para empezar a constituir un principio dinámico difícil de controlar.

La producción poética de Antonio Martínez Sarrión permite, o mejor, propicia, dispara esta línea de problemas por cuanto trabaja con una insistente y paradójica autorreflexión no tanto - aunque también - en torno a la literatura como sobre/desde la escritura. La visibilización de los diversos procedimientos de montaje que procura, por un lado, hace inviable la escisión, cuanto más sistemática más esquizofrénica, entre práctica y teoría, mientras que, por otro, pone en clave de conflicto, de espesor ideológico, las premisas naturalizantes y de transparencia ilusoria características de la escritura clásica o burguesa (Barthes, 1986). La aproximación, en fin, que estas páginas proponen, intenta menos explicar que señalar algunas de las estrategias retóricas puestas en juego por el dispositivo textual Antonio Martínez Sarrión, el cual, agrupándolas, subraya su interdependencia. Hablar, entonces, de la poesía de Antonio Martínez Sarrión sería, de forma escasamente metódica, hablar de $-y$, en cierto modo, desde su cruce- su mutua contaminación y su estallido.

1. Tanto en su formulación inicial de la mano del círculo de Bajtín como en su posterior adaptación a cargo de Kristeva, la noción de dialogismo aparece vinculada a una notable visibilidad de sus implicaciones ideológicas. Como sucede en Pound o en Faulkner, la articulación dialógica, plural, de un lenguaje con otros le hace perder su voluntad mítica poniendo en cuestión las premisas de unicidad y totalidad que le son inherentes en la escritura clásica. El cómo este trabajo a la vez multiplicativo y disgregador puede esbozar los presupuestos de una utopía social igualitaria es tema que sigue pendiente de desarrollos teóricos y prácticos. Concebir el espacio textual como lugar para la circulación no jerárquica de lenguajes implicaría posiciones que buscan enfrentarse a la táctica lingüística institucionalizada en las sociedades desarrolladas, donde la condición homogeneizante del idioma nacional y la cultura masiva enmascara las potencialidades de distintas formas de conflicto sígnico, es decir, social.

La práctica poética de Antonio Martínez Sarrión, de forma plurilógica, logra hacer de la intertextualidad y de la cita un principio constructivo/destructivo radical en la serie de poemas incluidos en Teatro de operaciones (1967), y especialmente en Pautas para conjurados (1967-1969), en Ocho elegías con pie 
en versos antiguos (1972), Una tromba mortal para los balleneros (1970-1973) y Canción triste para una parva de heterodoxos (1976). Por ejemplo, el discurrir poético se entrecruza con códigos y registros linguísticos tan diferentes como los que siguen:

a) Habla común:

no confies en la carga de la pipa

mira que está cargada de explosivos

mira que va a estallar

(«Aviso», Teatro de operaciones)

su personalidad que vaya usted a saber

(«Crónica fabulosa de Fernando Pessoa», Pautas...)

y qué más da, querida,

sé una vez razonable, qué más dará

(«Última hora», Una tromba mortal...)

b) Registro burocrático:

dado el ejecutivo bando del alcalde

dadas las circunstancias luctuosas

(«Final de verano», Teatro de operaciones)

la apelación

es denegada

(«Algo huele a podrido en Dinamarca», Una tromba mortal...)

c) Registro eclesiástico:

Laudetur

Genuflexio

Asperges tui

Por todos libéranos

Domine de morte aeternam

(«Destrucción tardía de alimañas», Una tromba mortal...)

d) Registro periodístico:

El aire saqueado, la huida de los WASP hasta lejanas cotas abrieron la ofensiva.

(«One for Shepp», Una tromba mortal...) 


\section{"ASALTOS A LOS FUERTES ARGENTINOS» \\ (...) «FUSILAMIENTOS EN AMMAN» «IMPOSICIÓN DE MANOS AL CARDENAL MÁS DÓCIL DE LA CURIA ROMANA" («Última hora», Una tromba mortal...)}

e) Referencias al código media culture: week-end, happy christmas, the late late show, country songs, Golden Years, box-calf, relaxing, revivals...

Poemas como «Hasta el más lerdo puede comprobar que se trata de un ejercicio de mala conciencia personal» o «No está lejana una Edad de Oro» de Pautas para conjurados pueden ser muestra de hasta qué punto se encuentran articulados el mecanismo dialogístico, la fragmentación sintáctica y la idea de desmantelamiento de la Escritura, de la Cultura, del Sujeto, de la Historia. La labor crítica es tal que se acerca a la blasfemia (Gea, 1994: 26). Para ello, la táctica de subrayar el principio de montaje, de extremarlo, hace emerger las fisuras de la enunciación, sus arenas movedizas. Así ocurre en «Por última vez los pájaros» (Teatro de operaciones) o en «Drenaje» (Una tromba...):

y una tromba mortal para los balleneros estalla y surgen muchos, submarinos, totales...

Desde un barroquismo actualizado, la recurrencia obsesiva a las nociones de muerte, deterioro o desastre configura una pesada atmósfera de desaliento en la que cobra singular relieve la urgencia de la reflexión sobre la poesía, la acción y la comprensión de lo histórico:

El sentimiento común aparte porque claro es la poesía ya saber algo periclitado (vide MacLuhan) fichas de un centón aburrido un producto romántico (en el manoseado sentido de la frase) Sin embargo lo subterráneo lo iniciático lo apenas insinuado ('Intelijencia dame el nombre exacto de las cosas!') necesarios obstáculos acicates a la hora de la acción («Ritual de los apocalípticos», Pautas...)

¿Por qué no repetir y repetir que es cómodo el sillón aunque paralizante? («II», Ocho elegías...)

\section{Historia}

ya tapiada viejo tiempo maldito

en interrogatorios a las sombras

(...) 
mientras la historia de los hombres sigue

ante sus ojos congelados

(«De la inutilidad de conspirar en librerías de viejo», Pautas...)

La escritura experimental, visiblemente intertextual y autorreflexiva que César Nicolás ha atribuido a la "generación sin unidad" (Nicolás, 1989) de los años setenta en la poesía española encuentra ejemplos insoslayables en la producción de Martínez Sarrión, que, sin embargo, se compagina difícilmente con la tendencia al escapismo que alguna vez se le ha achacado (García Barrio, 1989). Cuesta hablar de escapismo ante prácticas de escritura que, como ésta, problematizan de tal manera su posible unidad como discurso que promueven una problematización aguda de lo real, de su percepción —en todo caso mediada por la acción del propio discurso: ya discurso. Las formas de significar de este decir poético terminan resultando más decisivas que el supuesto significado de lo dicho.

A menudo, el gesto textual de esta escritura «se limita a imitar un gesto siempre anterior, nunca original; el único poder que tiene es el de mezclar las escrituras, llevar la contraria a unas con otras de manera que nunca se pueda uno apoyar en una de ellas (...), un texto está formado por escrituras múltiples, procedentes de varias culturas y que, unas con otras, establecen un diálogo, una parodia, una contestación» (Barthes, 1987: 69-71). Políticamente, una voluntad utópica de desapropiación, un continuo cuestionamiento de la propiedad resume estos procesos discursivos.

2. Si el funcionamiento simbólico del lenguaje se basa menos en procedimientos de significación (significante/significado, Saussure) que de significancia (ste-ste/do, Lacan) es posible deducir que el montaje textual, sometido a una cadena de desplazamientos y remisiones, no acaba nunca de ser definitivo, de anclar una encrucijada móvil que sólo cada lectura concreta localiza y actualiza. En este continuo juego dilatorio la tensión significante no deja de resistirse a la fijación del significado, no deja de hacerlo retroceder. El alcance de este proceso, que el fantasma de la lengua estándar intenta evacuar, adquiere un importante protagonismo en el habla común y puede llegar también a un vértigo insospechado a través de la escritura. A partir de un punto, el exceso significante desborda los códigos de lo previsto, desde su interior abisma la regla, la transgrede.

$\mathrm{Si}$, desde luego, dicha táctica no es general a todo texto, sí, al menos, puede detectarse en la escritura de Martínez Sarrión. Bajo la forma de una condensación, a menudo simultánea, de los niveles fónico, léxico y sintáctico, actúa — no sólo en ellos pero- con una opacidad palpable en los poemarios El centro inaccesible (1975-1980), Horizonte desde la rada (1980-1982) y De acedia (1984-1985). Los ejemplos podrían multiplicarse hasta la fatiga. Únicamente como guía: 
a) Fónica

contándose sus sueños donde tú aparecías desleído, inconcreto, sonriente, tendiendo los bracillos a los brazos amantes que te alzan a dioses antiguos y borrosos cuya riente huida entre las ondas dejó a la hermosa tierra un instante aterida y rotunda al siguiente, siempre a sus fieles fiel («Pacto», Horizonte desde la rada)

b) Léxica:

motetes al mar grave («Clave bien temperado», Horizonte...)

a guisa de horadado carozo («Signo en el cielo», Horizonte...)

peces de minio, (...) bulimias sin pudor ("Barato mar», De acedía)

c) Sintáctica:

La luz por un ventano cegadísimo con algo de oropéndola en el sueño alegre la papilla al niño lelo cuya baba-burbuja crece y crece y lista está y repleta cuando el ángelus estalla y promociona al campanero a vitalicia sopa de zapatos $y$ al uso de bonete fulgurante que aún puede rastrearse en los tapices con lupa de muy alta precisión.

( $\mathrm{El}$ arador de la sarna la tiene tomada con Francisco Delicado», El centro inaccesible)

En este último nivel son más que frecuentes poemas enteros que constan de apenas una o dos unidades oracionales. La concentración se extiende a un riguroso trabajo con la métrica, los esquemas acentuales y, a veces, hasta con 
la rima. De esta forma, el discurso aprende a aceptar y reivindicar su propia materialidad ante la resistencia de lo real inabordable:

terco mundo presente,

que fulgura y se esfuma tan tranquilo, negándose de plano $\rightarrow$ y con cuánto derecho-

al deshonesto oficio de pañuelo de lágrimas

(«Carpe diem», Horizonte desde la rada)

A su vez, el entramado dialogístico que constituye cada texto en cada contexto material y vivo reduce la cuestión de la densidad significante a estéril abstracción mientras ésta quede presa en términos estrictamente fónicos, léxicos, sintácticos o semánticos. El discurso poético arraiga en lo cotidiano desbordándolo. La materialidad de la palabra se hace dinámica y rebelde sólo en contacto con otra materialidad abierta: la de cada espacio histórico, por mínimo que sea, donde cada poema es (re)leído, es decir, es (re)escrito. El desnivel en la dependencia del contexto concreto del discurso poético y del discurso cotidiano es menos una frontera fija que un problema de grado: mayor en éste, menor en aquél, pero en cualquier caso inevitable como tal dependencia.

Es entonces este peso intratable de lo real lo que hace que el discurso se es-pese más allá de lo normalmente tolerable. El proceso de pérdida y entrega, cuya apertura («Educación primaria», «Dragón») se celebra en El centro inaccesible (Siempre acaba por amanecer, «Panamá Skyline»), encuentra su asunción más clara en la metáfora del horizonte apenas insinuado desde la rada que da título al poemario siguiente. Asunción de la grieta, del azar, de lo que no podrá ser dicho porque nombra la muerte, el vacío:

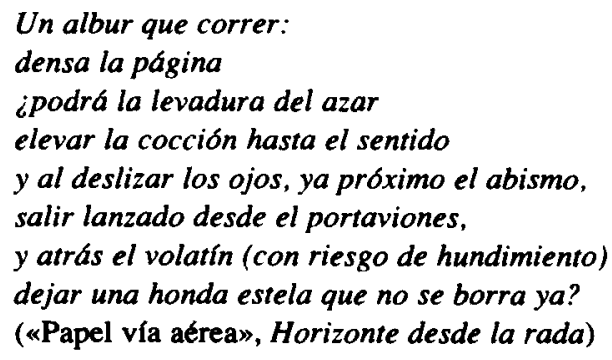

El texto, que surge guerreando y con clara cabeza («Condición básica»), presa de una inquietante turbiedad enunciativa, va tomando conciencia de su caducidad radical («Spleen», poemas finales de Horizonte desde la ra- 
da) para desembocar en la fría acidez que recorre, como un escalofrío lento, De acedía:

\author{
Pegajoso está el día, \\ untuosa \\ la noche adelantada por la bruma. \\ La paz, \\ de puro amenazada, inapreciable. \\ De los altos tapiales los dondiegos \\ bajan como una dádiva su aroma \\ que apenas bastará para cubrir \\ de un fugaz resplandor tanto cadalso. \\ («Cirineos», De acedía)
}

Poema, pues, como campo de concentración. En él, como escribía Barthes a propósito de las narraciones de Cayrol, la lectura «lo que intenta extraer es inagotable, quizás ésta es la verdad de esa conciencia aguda, obstinada, que jamás abandona el mundo y sin embargo no es capaz de reposar en él, jamás. [...] Ese mundo frágil, sensible, es un mundo resistente. [...] Todo lector de Cayrol, conducido hasta el borde del frío y de la inutilidad, se encuentra, al mismo tiempo, dotado de un calor y un sentido de la vida que le han dado el mismo espectáculo de alguien escribiendo [...] Quizá la primera razón para ello es que el Concentracionado no ha muerto; [...] las novelas de Cayrol son el paso mismo del acontecimiento concentracionario a la cotidianeidad concentracionaria: veinte años después de los Campos, encontramos en ellos hoy en día una determinada calidad de lo atroz, de lo grotesco o de lo absurdo, cuyo choque todavía recibimos ante ciertos sucesos 0 , aún peor, ante ciertas imágenes de nuestro tiempo" (Barthes, 1987: 229-233). En Martínez Sarrión, la espesura de esta concentración significante sigue siendo un recurso crucial hasta en los versos del largo poema que da cuerpo a Cantil (1995).

En conjunto, el trabajo significante opera, en fin, por medio de una dialogización no tan centrífuga como centrípeta, que pone en clave de conflicto el lugar que el discurso logocéntrico reserva para la transparencia y la transcendencia. A través de un cauce más sensible que conceptual el sentido patina, finalmente inapresable:

La poesía es fábrica de castigados muros

con alto tragaluz que sólo al azar filtra

la más perecedera luz del sueño.

(«Otra poćtica improbable», De acedía) 
En efecto, el resultado viene a constituir una profunda contestación de las premisas de plenitud representativa-referencial características del realismo ingenuo. El propio Martínez Sarrión aporta lúcidos argumentos que pueden ser de interés en un momento en que cierta poesía de la experiencia ensaya, desde mediados de los años ochenta en España, un regreso a este ya inofensivo modelo de escritura. Entre los tumores que lo esterilizan, destaca «el olvido de que un texto literario es, ante todo, un dispositivo verbal que no tiene por qué intentar reflejar una realidad anterior o simultánea privilegiada, ya que él mismo constituye otra (y no inferior ni superior) clase de realidad» (citado en Provencio, 1988: 37). El realismo funciona con la subordinación a una (concepción de) realidad a priori a la vez que la reafirma y obstaculiza la proyección de mediaciones simbólicas vinculables a otra(s concepciones de) realidad alternativa(s).

En esta cuestión, la práctica poética de Antonio Martínez Sarrión se opone a los modos de comprensión y existencia normales en un mundo donde la norma se mueve entre la generalizada indiferencia instrumentalista y el crimen colectivo diario. Con esto, su propuesta se articula, entre otras, con las escrituras subversivas contemporáneas de Manuel Vázquez Montalbán, Leopoldo María Panero o Jenaro Talens.

3. Escritura, montaje, representación... son palabras que he usado más arriba directa e indirectamente. La poesía de Martínez Sarrión multiplica y problematiza sin descanso las relaciones entre ellas. Maneja, por ejemplo, desde El centro inaccesible, un apego a lo descriptivo que deja en entredicho las bases ideales del mecanismo representativo clásico. Por otra parte, ya en Teatro de operaciones, las técnicas de collage conducen a una continua ruptura que desestabiliza la escena, haciendo del sujeto poemático no ya el dueño sino más bien la víctima de la representación. En este sentido, se ha comparado esta estrategia de escritura con algunas características del cine: «una realidad fotografiada en un film es el material de base, que fuera de las apreciaciones y el entorno del fotógrafo queda como una imagen fija, que posteriormente puede ser reinterpretada en otro entorno. [...] El paraíso así representado elimina toda añoranza de que cualquier tiempo pasado fue mejor. Martínez Sarrión actúa como un comediante, un artesano, que recoge toda una serie de materiales-base, los pule, organiza y recrea, creando en un nuevo escenario una nueva representación» (Canet, 1985: 220).

La escenificación de la memoria, su construcción discursiva, tanto en Teatro de operaciones (1967) como en Ejercicio sobre Rilke (1986-1988), se halla atravesada por una teatralidad consciente, que no pasa desapercibida, de modo que «ese carácter elimina de entrada, y es su mejor virtud, el patetismo de la nostalgia» (Talens, 1981: 220). Lo que está en juego y puede así comba- 
tirse es la condición absorbente, sub-yugante de la catarsis. Y es necesario aclarar que se trata de un juego perverso, «una doble escritura al mismo tiempo y en el mismo lugar: un poner límites a la representación y un poner límites a la crítica de los límites de la representación. Un juego a dos manos, en definitiva" (Asensi, 1986: 46).

Precisamente el espesor material de la textualización, metaforizada como muro, socava el riesgo de identificación hipnótica. Así viene teorizado en poemas como el titulado, a lo Eisentein, «Montaje de atracciones» (Ejercicio sobre Rilke) o en «Paso en falso» (De acedía), éste último toda una revisión de una agitada trayectoria poética:

\section{El horizonte trajo un galeón airoso} mas pronto levantó la pestilencia su murallón cinabrio contra toda ilusión.

En sentido temático, lo que hace con la infancia Teatro de operaciones lo hace Ejercicio sobre Rilke con la juventud y la primera madurez: exorcizarla. O mejor: darle forma poética. Es decir, transformarla. Retomando estrategias de aquél, este último poemario consigue provocar un efecto de distanciamiento a través de técnicas como el uso de verbos en forma impersonal o la introducción de personajes-representantes: yo que recuerda («Viajes con una histérica»), nosotros («Perversiones de posguerra entre gentes de orden»), ellos-tú («Carne de lidia»), nosotros, un espectro visceral («El lapidado»)... que habitan el paso del tiempo, la siente inminencia de la muerte.

De acuerdo con los presupuestos democráticos y participativos del teatro de Brecht o las películas de Godard o Tanner, lo puesto en escena es menos una acción que una situikión, menos un paisaje que una mirada. El uso crítico de las premisas del espectáculo clásico "reside en expresar la relación de la acción que se representa con la que está dada en el hecho de representar. [...] Que el que muestra sea mostrado" (Benjamín, 1990: 27). Si hay representación - y la hay-, se da principalmente para negar su presunta autoridad, no para enajenarlo sino para abrirse ante el espectador y mostrar los entresijos de su producción, de su carácter de artefacto concreto:

Mares como una nécora chorreante y vaciada cuyos dentros se asan a los ojos del público para que se percate de que no hay engañifa, de que quien habla fuerte es que gasta pistola y que puede emplearla y que piensa emplearla. («Mares que no aparecen en los atlas», Ejercicio sobre Rilke) 
Como ocurre también en poéticas como la de Gil de Biedma, el efecto de distancia se apoya con frecuencia en el recurso a la ironía. Ésta, como el juego y lo cómico, no permite que ilusión alguna perdure demasiado. Su poder desestabilizador, no calmante, índice de conflictos tan simbólicos como sociales, es incesante. De hecho, lo simbólico y lo social no podrían deslindarse. Como se sabe, «no acepta quedar petrificada en el mármol ni paralizada en la preocupación inoperante (...). Es imposible habituarse a ella y encerrarla de una vez por todas en un concepto; nos mantiene ágiles, y siempre alerta» (Jankelevitch, 1983: 52-56). La poesía de Antonio Martínez Sarrión nos ayuda a seguir alerta ante estas tensiones, en ellas, a imaginarlas y vivirlas en formas nuevas.

\section{REFERENCIAS BIBLIOGRÁFICAS}

Asensi, MANUEL: «El juego y el decir sí/no de A. M. Sarrión». Zarza Rosa 6, 1986: 37-47.

BARTHES, Roland: El grado cero de la escritura. Madrid: Siglo XXI, 1986.

—: El susurro del lenguaje. Barcelona: Paidós, 1987.

BenJAMIN, Walter: Tentativas sobre Brecht (Iluminaciones III). Madrid: Taurus, 1990.

CANET, JosÉ LUIS: «Una nueva aproximación a la poesía de Martínez Sarrión». Ideologies and Literature 1-2, 1985: 218-229.

GaRcia BERRIO, ANTONIO: «El imaginario cultural en la estética de los novísimos», Insula 508, 1989: 13-15.

Gea, Juan CaRlos: «Antonio Martínez Sarrión: guardador, sacerdote, blasfemo». Prólogo a Martínez Sarrión, A.: Antología poética. Albacete: Ediciones de la Diputación de Albacete, 1994: 9-61.

JANKELEVITCH, WLADIMIR: La ironía. Madrid: Taurus, 1983.

Mariniello, Sil vestra: El cine y el fin del arte. Madrid: Cátedra, 1992.

MARTÍNEZ SARRIÓN, ANTONIO: El centro inaccesible (Poesía 1967-1980). Madrid: Hiperión, 1981.

-: Horizonte desde la rada. Madrid: Trieste, 1983.

-: De acedia. Madrid: Hiperión, 1986.

—: Ejercicio sobre Rilke. Pamplona: Pamiela, 1989.

-: Cantil. Granada: Comares, 1995.

NiCOlÁs, CÉSAR: «Novísimos (1966-1988): notas para una poética», Ínsula 505, 1989: 11-14.

Provencio, Pedro: Poéticas españolas contemporáneas (La generación del 70). madrid: Hiperión, 1988.

RosSI-LANDI, FerRuCCIO: Ideología. Barcelona: Labor, 1980. 
Talens, Jenaro: «(Desde) la poesía de Antonio Martínez Sarrión». Prólogo a Martínez Sarrión, A.: El centro inaccesible (Poesía 1967-1980). Madrid: Hiperión, 1981: 7-37.

Talens, Jenaro/Company, Juan Miguel/Hernández, Vicente: «Lenguaje literario y producción de sentido". En Díez Borque, José María (ed.): Métodos de estudio de la obra literaria. Madrid: Taurus, 1985: 523-551. 